\title{
Catálogo da obra de Manoel Victor de Jesus (c. 1760 a 1828)
}

Luciana Braga Giovannini'

DOI 10.20396/eha.vil4.3363

Pouco se sabe sobre a vida de Manoel Victor de Jesus. Não se conhece o local e o dia do seu nascimento porque não foram encontrados documentos que nos informem sobre sua origem e filiação como batismo, certidão de nascimento, óbito e inventário. Entende-se que ele tenha nascido por volta de 1760 devido a um documento com data de 1795 - o "Rol dos Confessados da Freguesia de Santo Antônio da Villa de São Jozé" ${ }^{\prime 2}$, no qual o pintor se declara com trinta e cinco anos de idade. $O$ artista faleceu no dia 27 de abril de 1828, possivelmente com 68 anos. ${ }^{3}$ Ele não foi casado, não teve filhos e viveu na companhia de seu escravo, Gregório José da Paixão, na rua de Trás da Vila de São José4, atual rua Jogo de Bola da cidade de Tiradentes. Em 1800, obteve do Governador e Capitão Ceneral da capitania de Minas Cerais uma carta patente para assumir o posto militar de alferes. ${ }^{5}$

Para compensar a escassa documentação, o artista deixou uma obra significativa que reunimos em um catálogo, fruto de pesquisa realizada no curso de pós-graduação da Universidade Federal de São João del-Rei. A dissertação intitulada "Os Mistérios do Rosário: Visão, Contemplação e Invocação" traz o estudo iconológico das pinturas de teto da igreja do Rosário de Tiradentes, cuja decoração da nave é atribuída a Manoel Victor de Jesus. No período em que a pesquisa foi realizada, entre 2015 e 2017, a pintura encontrava-se em péssimo estado de conservação, dificultando o seu estudo. Percebemos, então, a necessidade de pesquisar o conjunto da sua obra. Foi quando deparamo-nos com um corpus de obras relativamente vasto, disperso e pouco conhecido que acabamos por reunir e apresentar como anexo da dissertação. Deste modo, produzimos um catálogo que reúne praticamente toda a sua produção artística localizada na vila de São José e região, tanto as documentadas como as atribuídas, com o intuito de colaborar para a definição do perfil estilístico e para

\footnotetext{
1 Doutoranda em História pela Universidade Federal de Minas Gerais (UFMG), com apoio da FAPEMIG.

2 Arquivo do Instituto Histórico e Geográfico de Tiradentes (IHGT). Rol dos Confessados de 1795, pág. 42. Disponível em: [http://ihgt.blogspot. com.br/2014/08/rol-dos-confessados.html]. Acesso em: 16 de ago. 2016.

3 Arquivo Eclesiástico da Diocese de São João del-Rei, MG. Livro de Assentamentos de Irmãos da Irmandade de Nossa Senhora do Rosário, 1812-1885, Caixa 01/ Livro 06.

4 Arquivo do Instituto do Patrimônio Histórico e Artístico Nacional (IPHAN) de Tiradentes, MG. Arquivos da Câmara Municipal - Caixa I, 17701819 (documentos digitalizados).

5 Arquivo Histórico Ultramarino, Minas Gerais, Caixa 154/doc. $n^{\circ} 34$

6 GIOVANNINI, Luciana Braga. Os Mistérios do Rosário: visão, contemplação e invocação. Estudo iconológico das pinturas de forro da capela de Nossa Senhora do Rosário dos Pretos da Vila de São José, Comarca do Rio das Mortes - 1750 a 1828. $400 f$. Dissertação (mestrado em História) - Universidade Federal de São João del-Rei (UFS]), São João del-Rei, 2017.
} 
a composição e delimitação do repertório de imagens do pintor (fig.01).

Poucos estudos tinham sido desenvolvidos sobre o artista até o ano de 2015. Olinto Rodrigues dos Santos Filho foi quem o identificou, removendo-o da poeira dos arquivos que mantinha o seu nome encoberto. Em 2008, organizou uma exposição em comemoração dos 180 anos de morte do pintor promovida pelo Instituto Histórico e Geográfico de Tiradentes (IHGT), que resultou na publicação de um prospecto contendo informações sobre a vida e a obra do artista, dispostas cronologicamente.7 Santos Filho é o responsável pela atribuição da maior parte da produção artística de Manoel Victor de Jesus na região centro-sul de Minas Gerais e essa publicação constituiu o ponto de partida para a localização de suas obras.

Em 2012, Kellen Cristina Silva realizou um estudo sobre as pinturas de teto da igreja de Nossa Senhora das Mercês localizada na cidade de Tiradentes, contribuindo para o conhecimento da sua obra e inserindo o artista, definitivamente, na historiografia da arte do período colonial, em Minas Gerais. ${ }^{8}$ É importante ressaltar que Manoel Victor foi considerado um dos expoentes do estilo rococó na região de São João del-Rei, ao lado de Joaquim José da Natividade (1771-1841), por Myriam Ribeiro de Andrade ${ }^{9}$ e, recentemente, Kellen o reconheceu como um dos membros da "escola artística" do Rio das Mortes junto aos pintores Venâncio José do Espírito Santo (1783-1879) e Natividade. ${ }^{10}$

O desafio de produzir um catálogo da obra de um artista é imenso. Dificilmente pode-se considerá-lo finalizado; na verdade, parece-nos interminável. Concluído o mestrado, outras obras atribuídas ao artista foram localizadas, como por exemplo, a ilustração do frontispício do compromisso da irmandade de São Conçalo Garcia da vila de São João del-Rey, produzida em 1783 e atribuída, ao pintor, por Márcia Almada. O desenho encontra-se sob os cuidados da Biblioteca Nacional de Portugal e pode ser visualizado no site "Manuscritos do século XVIII". "Soube-se também da existência de pinturas que foram atribuídas a outros artistas, mas que podem ter sido produzidas por Manoel Victor, ou realizadas por algum discípulo do mestre a partir de seus desenhos. Existem ainda algumas obras de autores desconhecidos com características que indicam a possibilidade de

\footnotetext{
7 SANTOS FILHO, Olinto Rodrigues dos. Manoel Víctor de Jesus: 180 anos de morte. Catálogo de exposição de comemoração. Tiradentes, MC: Instituto Histórico e Geográfico de Tiradentes (IHCT), 2008.

8 SILVA, Kellen Cristina. A Mercês crioula: estudo iconológico da pintura de forro da igreja de Nossa Senhora das Mercês dos Pretos Crioulos de São José Del Rei, 1793-1824. 271f. Dissertação (mestrado) - Universidade Federal de São João del-Rei, 2012.

9 OLIVEIRA, Myriam Andrade Ribeiro de. O Rococó religioso no Brasil e seus antecedentes europeus. São Paulo: Cosac \& Naify, 2003 , p.286.

10 SILVA, Kellen Cristina. $O$ caminho das flores: estudo iconológico sobre a "Escola de Artes do Rio das Mortes" e o modelo intencional de encomenda - Minas Gerais (c.1785-c. 1841). 435f. Tese (doutorado em História). Universidade Federal de Minas Gerais (UFMG), Belo Horizonte, 2018.

11 Disponível em: [http://iluminuras.art.br/albums/compromisso-reformado-da-irmandade-de-sao-goncalo-garcia-da-vila-de-sao-joao-deel-rey/]. Acesso em: 13 de dez. de 2019.
} 
terem sido produzidas por um ateliê coordenado pelo pintor, o qual foi qualificado, pelos comitentes que o contrataram, como "professor da pintura". ${ }^{12}$

Por conseguinte, o catálogo continua incompleto; e a pesquisa, em andamento. $\mathrm{O}$ artigo que Ihes segue diz respeito ao que foi pesquisado na pós-graduação e o que esperamos realizar deste ponto em diante, tendo como objetivo primordial o conhecimento do perfil estilístico e do corpus de imagens de um pintor recém descoberto pela historiografia da arte colonial de Minas Cerais. É preciso, portanto, retirá-lo do lugar em que ele se encontra, como anexo de uma dissertação de mestrado, e reeditá-lo como um autêntico Catalogue Raisonné: instrumento primordial para o conhecimento de um artista. ${ }^{13}$ Coli nos fala que "para que os estudos de história da arte no Brasil sejam feitos com o rigor necessário, os catalogues raisonnés são fundamentais. É imperativo que pesquisadores se dediquem a essa tarefa". ${ }^{14}$

Para atender aos propósitos mencionados, o catálogo foi organizado de forma a constar as seguintes informações: imagem; localização; comitente; suporte; técnica; data; restaurações; documentação, ou atribuições das obras; autenticidade das atribuições ${ }^{15}$; tema e breve descrição formal e iconográfica de cada pintura (fig.02 e 03). O objetivo era produzir um inventário, o mais completo possível, da obra do artista. Entretanto, as restrições impostas pelo formato de um anexo nos obrigou a torná-lo mais enxuto. As imagens foram dispostas com o intuito de conciliar o tempo e o espaço, ou seja, respeitar a cronologia da sua produção, mas reunir, em cada templo, todas as obras que foram encomendadas pelas irmandades estabelecidas naquele lugar. Dessa forma, começamos pela matriz de Santo Antônio por ser o local onde Manoel Victor iniciou os seus trabalhos como pintor e, também, porque praticamente todas as obras presentes neste templo possuem documentação. Foram essas pinturas que nos permitiram realizar um estudo comparativo seguro com aquelas que foram atribuídas ao artista. Por meio delas, confirmamos as atribuições, contestamos outras e continuamos pesquisando as obras que têm aparecido desde então. ${ }^{16}$

As pesquisas demonstram que Manoel Victor de Jesus teve uma participação relevante na

\footnotetext{
12 SANTOS FILHO, Olinto Rodrigues dos. Manuel Victor de Jesus, pintor mineiro do ciclo Rococó. In: Barroco 12, 1983, p.238.

$13 \mathrm{COLI}$, Jorge. O que é um “Catalogue Raisonné" e para que serve. In: JÚNIOR, Martinho Alves da Costa (org.). Amável Leitor: ensaios de arte e cultura. Juiz de Fora: Editora UFJF, 2019, p. 269.

$14 \ldots$ O que é um "Catalogue Raisonné" e para que serve, 2019, p. 277.

15 O frontispício do compromisso da irmandade de Nossa Senhora das Dores da Vila de São José (1801) foi incluído no catálogo por ter sido atribuído ao pintor. Porém, durante a análise formal do desenho, apresentamos nossas considerações a respeito da obra contestando a sua autoria.

16 Nos limitaremos a expor, neste artigo, as análises e as imagens das obras presentes na matriz de Santo Antônio da cidade de Tiradentes com o intuito de apresentar ao leitor as principais características da obra de Manoel Victor de Jesus. Para conhecer o catálogo complet, consulte Giovannini (2017)
} 


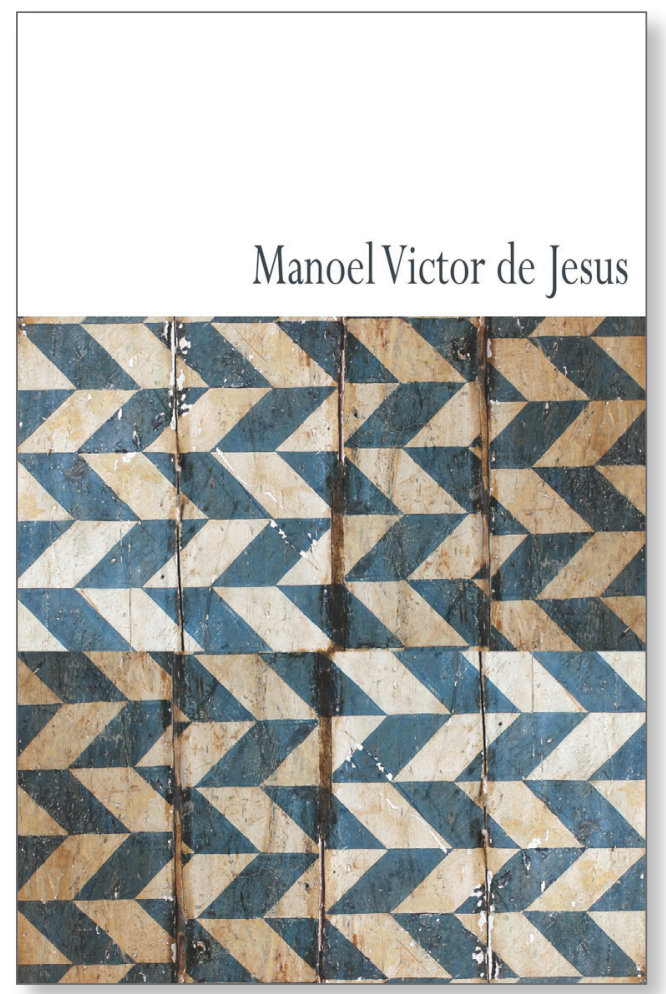

[Figura 1] Manoel Victor de Jesus. Capa do Catálogo da obra de Manoel Victor de Jesus (c. 1760 a 1828), 2017.
Consistório da Irmandade do Santíssimo Sacramento - 1782 localização

data e comitente

O forro em formato de gamela tem cinco compartimentos, um central e quatro laterais. No forro central, os artistas representaram um anjo segurando um Ostensório. Nos espaços em torno do forro do Anjo, quatro narrativas do Antigo Testamento: Isaac abençoa Jacó, A destruição de Sodoma 0 Encontro de Eliezer e Rebeca, e Judite e Holofernes. As narrativas bíblicas foram inseridas no interior de uma moldura em forma de rocalhas. No forro localizado acima do retábulo, foram pintados três símbolos de Jesus Cristo: o Cordeiro, a Fênix e o Pelicano.

\section{Documento:}

Instituto do Patrimônio Histórico e Artístico Nacional (IPHAN), Tiradentes - MG

1. Livro de Receitas e Despesas da Irmandade do Santíssimo Sacramento, 1779-1846.

2. Livro de Recibos da Irmandade do Santíssimo Sacramento, 1779-1846.

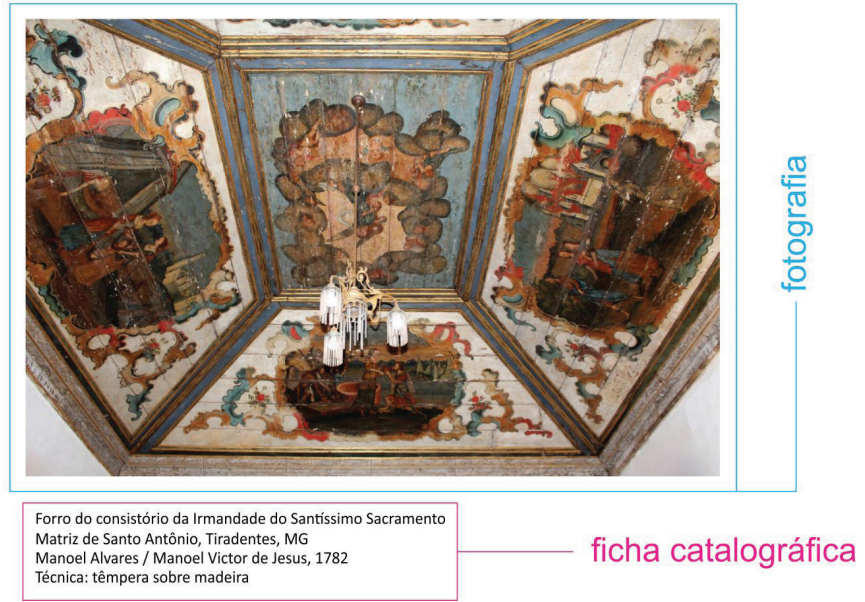

tema ou título

Painel Central - Anjo

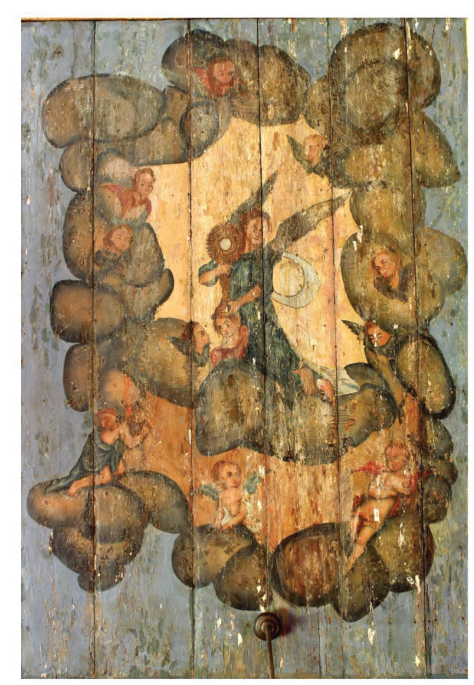

[Figuras 2 e 3]

Modelo de editoração do Catálogo da obra de Manoel Victor de Jesus (c. 1760 a 1828),
O forro central, de formato retangular, simula a abertura para o céu com anjos pairando sobre nuvens que cingem a figura central: um anjo segurando o Ostensório. A figura do anjo é destacada por um fundo claro que concede leveza à imagem. A pintura está muito danificada impossibilitando uma análise mais detalhada. Das nuvens, podemos ver apenas suas formas arredondadas, rígidas e de cores escuras indicando que as camadas de cores claras, que modelam, conferem volume e leveza às formas, se perderam Os anjos, na parte inferior, estão deitados, apoiados e ajoelhados nas nuvens, todos com o olhar voltado em direção à figura no centro da composição. Na parte superior, cabecinhas aladas envolvem o personagem principal e um anjo ajuda a sustentar o Ostensório, que está apoiado em sua cabeça. 
produção artística da vila de São José. Os poucos documentos que existem revelam que o pintor iniciou a sua trajetória trabalhando para as irmandades mais privilegiadas da vila. Com o passar dos anos, realizou trabalhos para outras congregações de menor projeção social, representadas por negros, mulatos e pardos. Existe um documento que atesta a sua presença na vila de São João del -Rei em 1775, quando ainda era jovem e esteve envolvido em algumas querelas ${ }^{17}$; mas foi em 1782 , com 22 anos de idade, que o artista apareceu trabalhando nas pinturas de forro do consistório da irmandade do Santíssimo Sacramento, localizado na matriz de Santo Antônio da atual cidade de Tiradentes, em colaboração com Manoel Alvares. ${ }^{18}$ No entanto, Olinto nos conta que o pintor já havia prestado serviços para a referida irmandade em $1781 .{ }^{19}$

O seu mestre é desconhecido, mas o intervalo entre os dois primeiros documentos que referenciam a sua presença na região, compreende um período de seis anos, tempo normalmente dedicado ao aprendizado da pintura na capitania de Minas Cerais. ${ }^{20}$ Trata-se, portanto, do primeiro indício de que o artista tenha se formado na comarca do Rio das Mortes. Além disso, existe uma particularidade que o distingue da maioria dos pintores desse período. Manoel Victor não circulou pela região mineradora, esteve atuando nas duas principais vilas da comarca, São José e São João del-Rei, de 1782 até o ano de sua morte, em 1828. O artista trabalhou initerruptamente durante 46 anos nas referidas vilas e a sua memória e cultura visual são consequência das obras de arte que foram vistas na região, da circulação dos impressos europeus e dos tratados de arte, assim como das relações estabelecidas com o seu mestre, os seus discípulos e os artistas que circularam pelo sul de Minas Gerais. Quando o pintor iniciou as suas atividades na matriz de Tiradentes, provavelmente já se encontrava formado, pois, logo em seguida, ainda em 1782, assumiu a encomenda da pintura de forro da sacristia da irmandade do Santíssimo Sacramento ${ }^{21}$, tornando-se, a partir dessa data, o principal decorador desse templo.

A obra nos permite entrever os principais aspectos estilísticos do pintor (fig.04). Veja os detalhes das figuras que representam "O sacrifício de Abraão". Eles evidenciam o seu estilema: os

\footnotetext{
17 SILVA, Kellen Cristina. Um Jesus Esquecido: A Trajetória do Pintor Manoel Victor de Jesus na Vila de São José del-Rei e Entorno, século XIX. In: Revista Kaypunku / Volumen 3 / Número 2 / Junio 2016, pp. 285-319, p. 308.

18 Arquivo do Instituto do Patrimônio Histórico e Artístico Nacional (IPHAN), Tiradentes, MG. Livro de Receitas e Despesas da Irmandade do Santíssimo Sacramento, 1779-1846. / Livro de Recibos da Irmandade do Santíssimo Sacramento, 1779-1846.

19 SANTOS FILHO. Manuel Victor de Jesus, pintor mineiro do ciclo Rococó, p.232.

20 Existe um único documento que nos informa sobre o tempo de aprendizado do ofício de pintor na capitania de Minas Gerais. Trata-se de uma "obrigação de aprendizagem" acordado entre Manoel Rabello de Souza e o pai de João Batista de Figueiredo, seu aprendiz, com data de 1760, documento anexado a um processo que envolveu o mestre e o seu discípulo: uma "Ação de Libelo". O contrato deixa registrado que o tempo destinado ao aprendizado de pintor seria de seis anos. Sobre o assunto, consultar Célio Macedo (2000) e Hudson Martins (2013).

21 Arquivo do Instituto do Patrimônio Histórico e Artístico Nacional (IPHAN), Tiradentes, MG. Livro de Receitas e Despesas da Irmandade do Santíssimo Sacramento, 1779-1846 e Livro de Recibos da Irmandade do Santíssimo Sacramento, 1779-1846.
} 


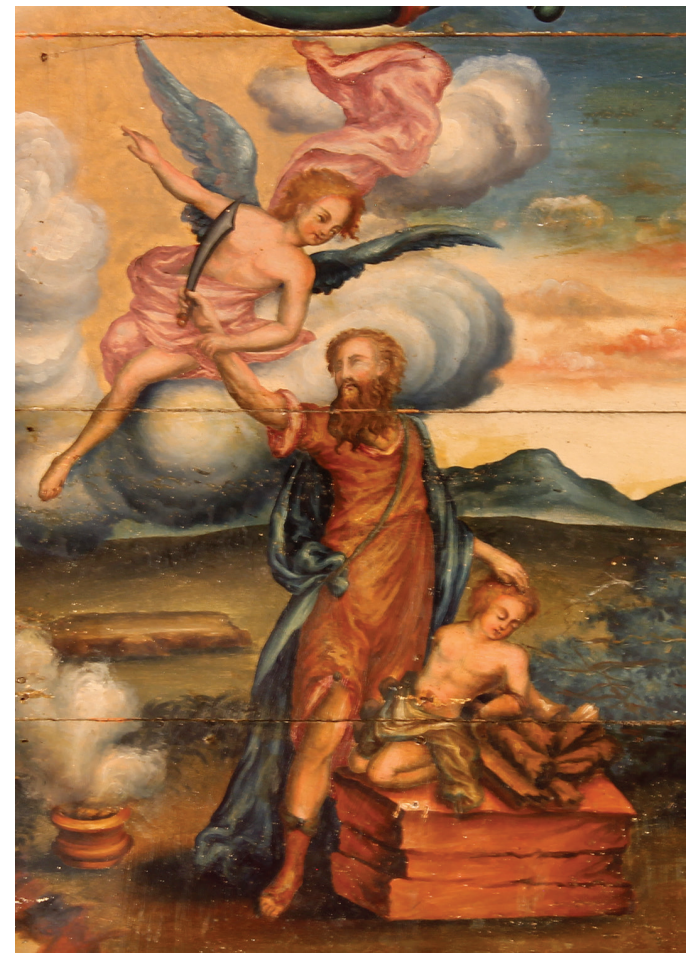

[Figura 4] Manoel Victor de Jesus. O sacrifício de Abraão (detalhe), 1782.

Pintura de forro da sacristia da irmandade do Santíssimo Sacramento, Matriz de Santo Antônio, Tiradentes, MG. Técnica: têmpera sobre madeira.

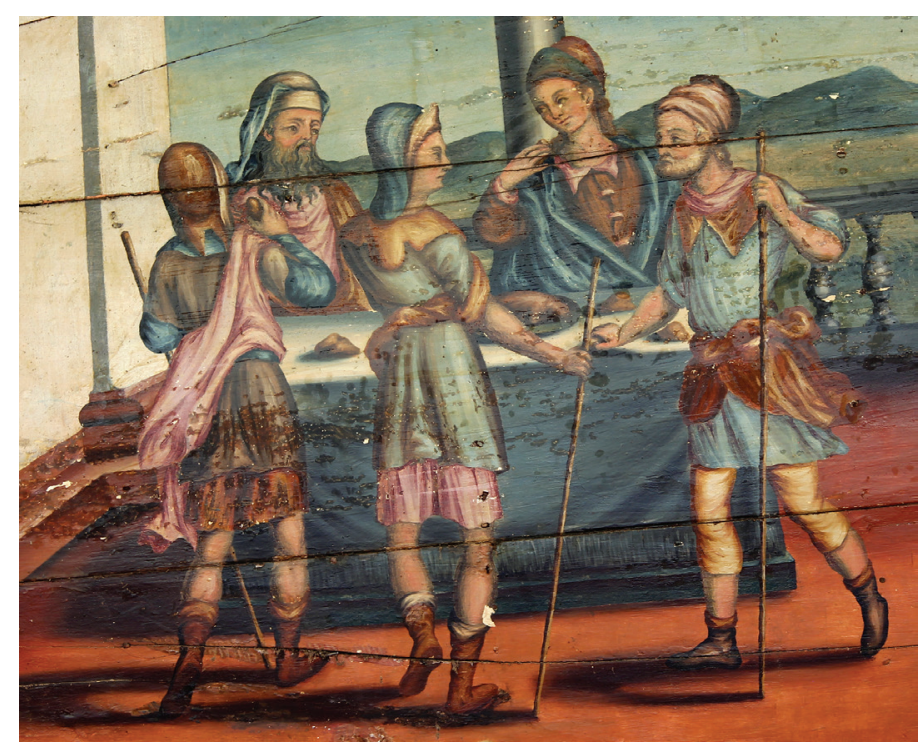

[Figura 5] Manoel Victor de ]esus. A aparição de Mambré (detalhe), 1782.

Pintura de forro da sacristia da irmandade do Santíssimo Sacramento, Matriz de Santo Antônio, Tiradentes, MG. Técnica: têmpera sobre madeira.

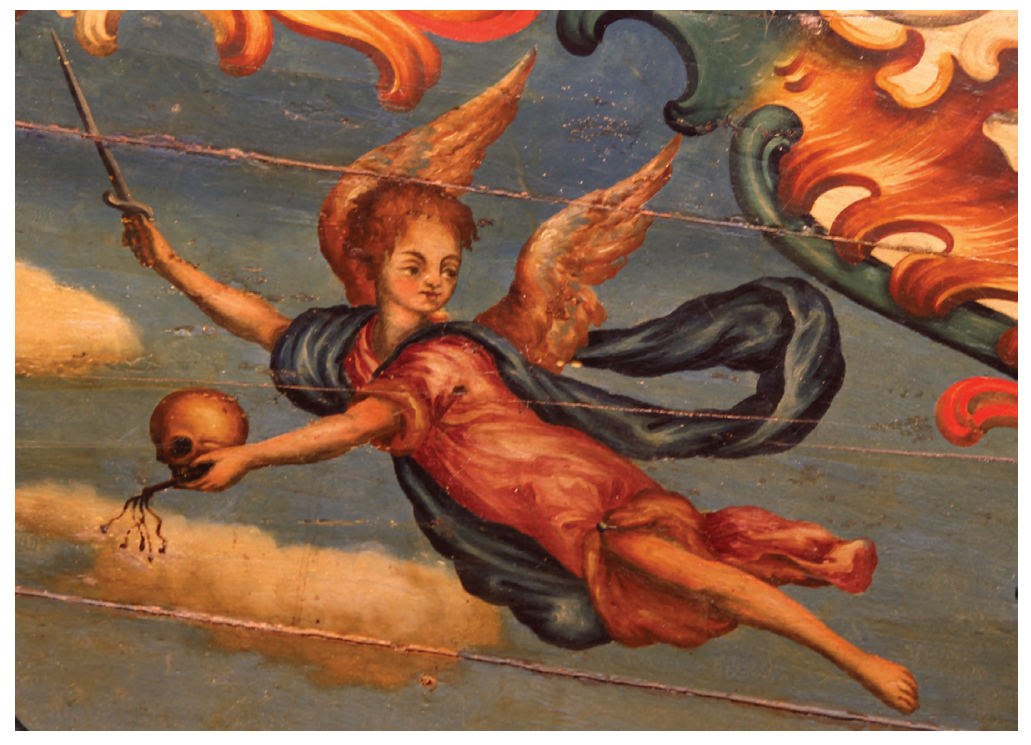

\section{[Figura 6]}

Manoel Victor de Jesus. A peste e o poder divino (detalhe), 1782.

Pintura de forro da sacristia da irmandade do Santíssimo Sacramento, Matriz de Santo Antônio, Tiradentes, MC. Técnica: têmpera sobre madeira. 
cabelos ruivos e levemente ondulados do anjo, a boca pequena e bem desenhada, os olhos amendoados e as sobrancelhas alongadas. Características recorrentes nas figuras angélicas criadas por ele, representando, simultaneamente, doçura e melancolia. Nesta pintura, nota-se que as linhas do desenho são fluidas, contradizendo algumas obras que apresentam um desenho de linhas precisas. Percebe-se também a leveza na representação das nuvens e da fumaça do incensário, que se dissolve no espaço. $\mathrm{O}$ artista representou a musculatura dos braços e das pernas de Abraão, revelando uma interpretação anatômica que não é constante no decorrer da sua produção artística, sinalizando a possibilidade da atuação de outros pintores, provavelmente os seus aprendizes.

Essa variabilidade pode ser percebida no painel ao lado, "A aparição de Mambré", em que o grupo figurativo apresenta os corpos endurecidos pelo desenho, resultando numa atitude muito artificial dos personagens e revelando a dificuldade do pintor de manter a unidade estilística no conjunto de sua obra (fig.05). Outro detalhe, contumaz nas pinturas de Manoel Victor, é a representação de uma das pernas desnudas, do joelho para baixo, e o tecido preso por um objeto de formato circular. Pormenor observado na figura de Abraão e no anjo do painel ao lado, representando "A peste e o perdão divino" (fig.04 e 06). Na figura do cordeiro, o cuidado com os detalhes revela a correlação da imagem com a referência literária, fidelidade presente em toda a sua produção pictórica. O animal foi pintado exatamente como diz o texto: "preso pelos chifres no arbusto". Para reproduzir a planta, o artista pintou um emaranhado de galhos em tons castanhos perpassando o corpo do animal que se movimenta como se tentasse se desvencilhar (fig.07).

No que diz respeito ao estilema do pintor, gostaria de destacar também a pintura de forro do consistório da irmandade do Bom Jesus dos Passos (1804-1805), onde o artista pintou a figura de um anjo adulto que revela, ao observador, a verdadeira face de Cristo - "O véu de Verônica" (fig.08). ${ }^{22}$ $\mathrm{O}$ anjo de feições delicadas, cabelos longos e olhar benevolente, possivelmente faz uma alusão à piedade e à compaixão da mulher que secou o suor de Cristo. O ser celestial nos traz à lembrança algumas particularidades estilísticas que estarão presentes em pinturas posteriores, a saber: a veste amarrada com um laço de tecido esvoaçante, a gola no pescoço arrematada por um botão de formato circular e a dobra da manga na mesma cor da gola. Essas características podem ser observadas na representação da corte celestial pintada nos forros das igrejas das Mercês de Tiradentes e de Nossa Senhora da Penha de França do Bichinho; bem como nos anjos adultos presentes em outras obras atribuídas ao artista. Manoel Victor parece ter imprimido a sua assinatura na figura deste anjo em 


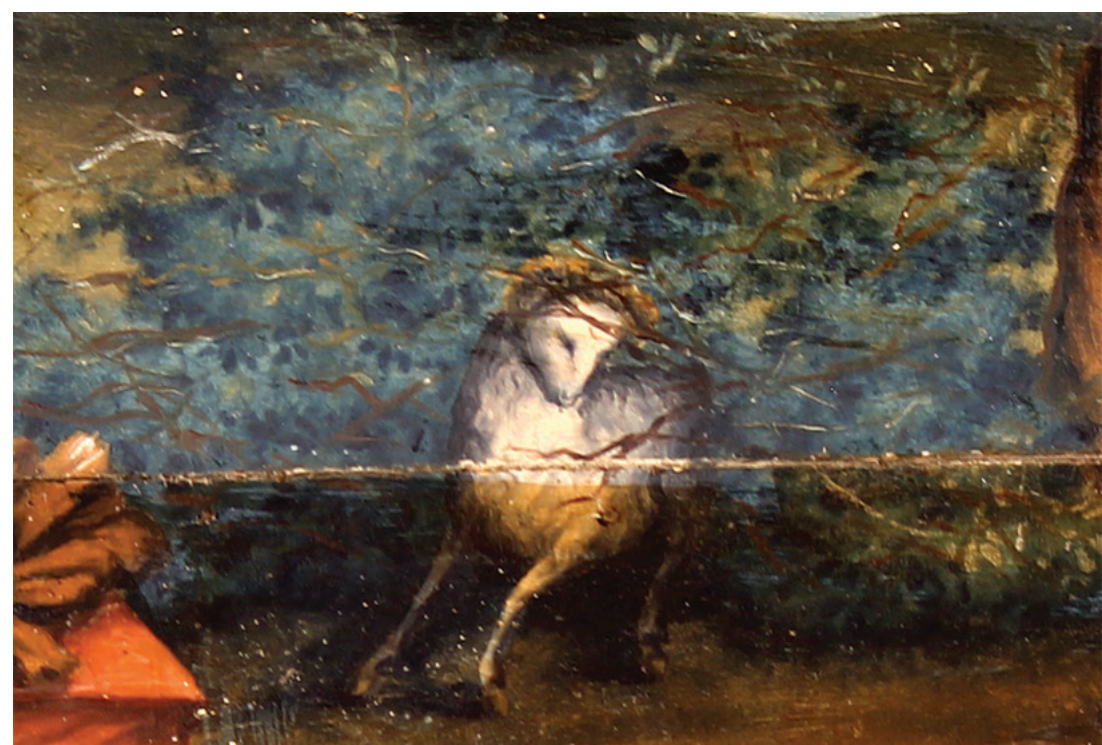

[Figura 7] Manoel Victor de Jesus. O sacrifício de Abraão (detalhe), 1782.

Pintura de forro da sacristia da irmandade do Santíssimo Sacramento, Matriz de Santo Antônio, Tiradentes, MG. Técnica: têmpera sobre madeira.

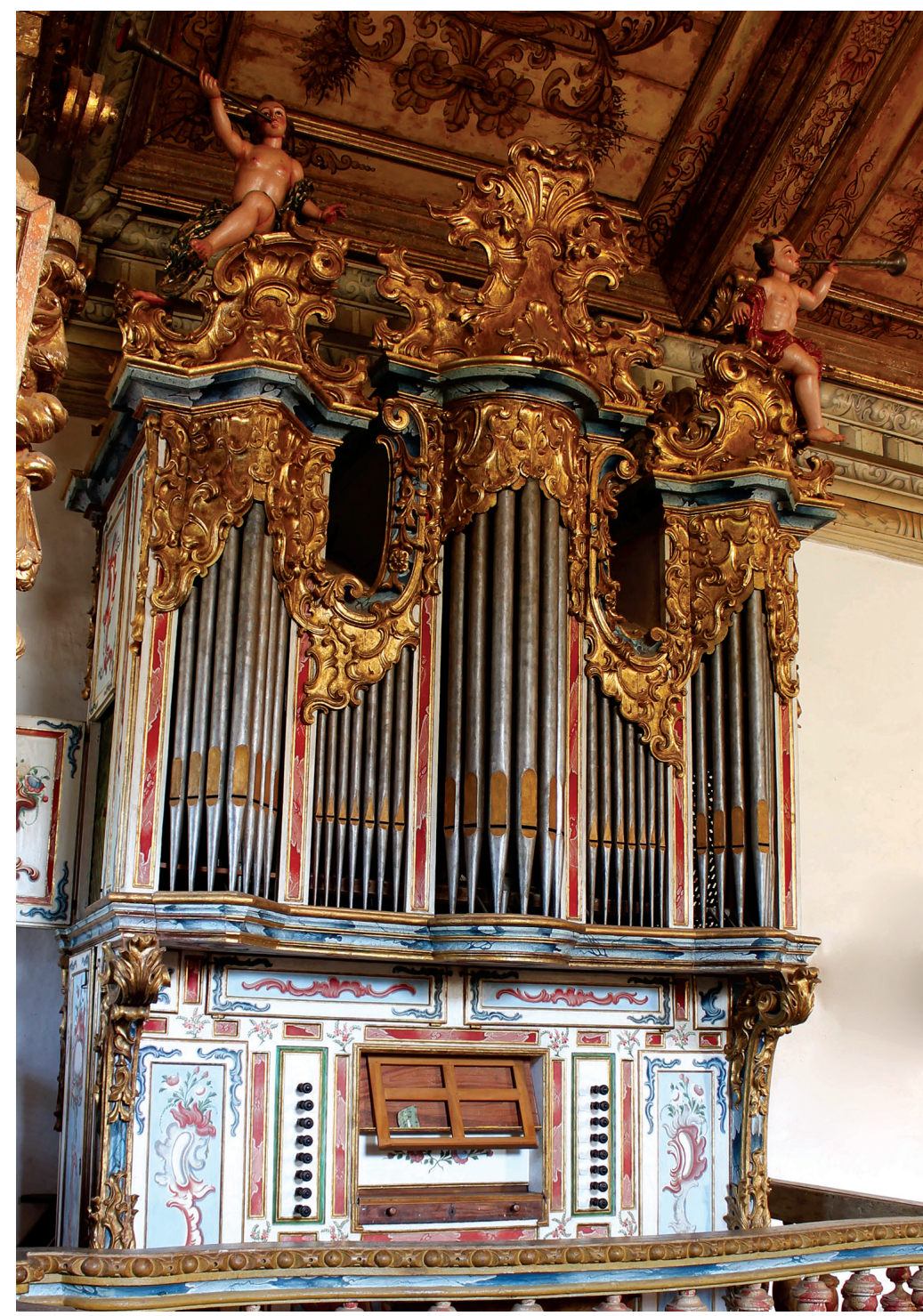

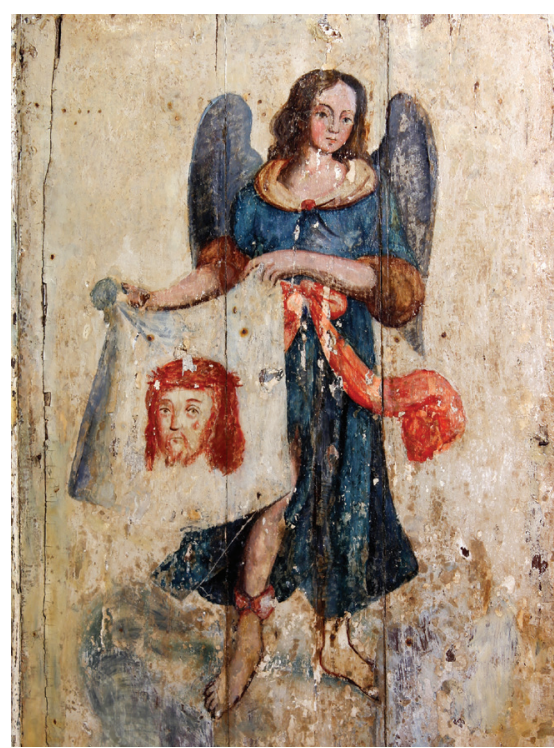

[Figura 8] Manoel Victor de Jesus. 0 véu de Verônica, 1804-1805.

Pintura de forro do consistório da irmandade do Bom Jesus dos Passos, Matriz de Santo Antônio, Tiradentes, MG. Técnica: têmpera sobre madeira.

\section{[Figura 9]}

Manoel Victor de Jesus. Pintura da caixa do órgão da Matriz de Santo Antônio, Tiradentes, MG, 1797-1798.

Técnica: douramento, carnação e têmpera sobre madeira. 

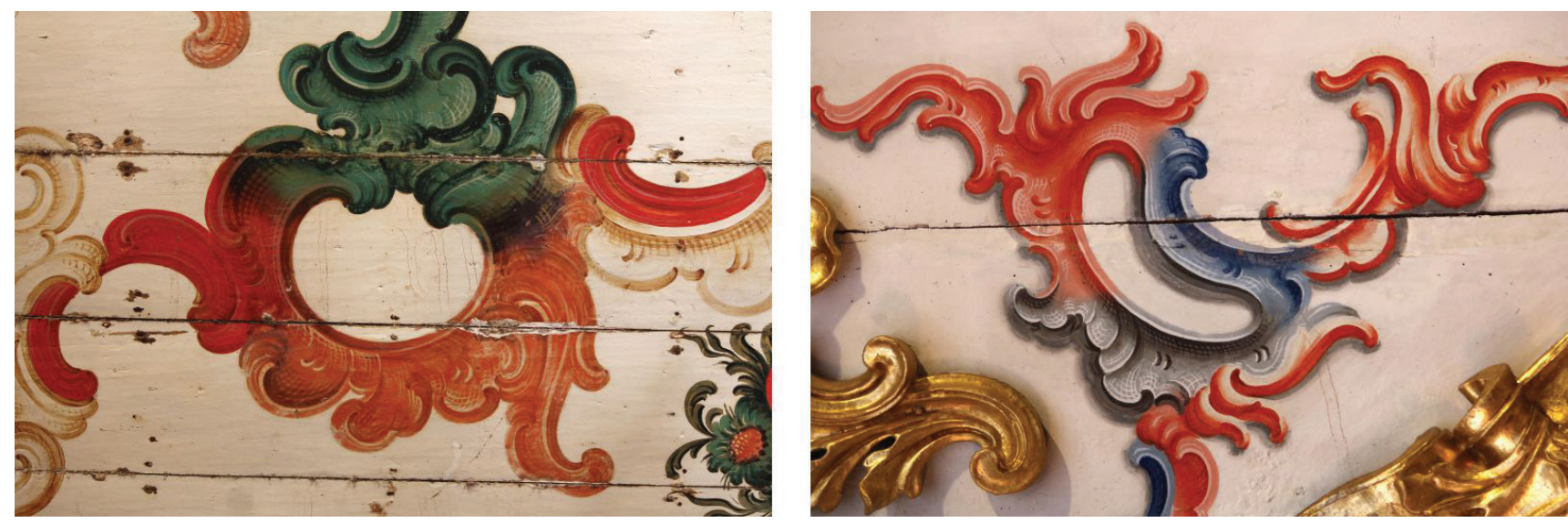

[Figura 10] Manoel Victor de ]esus. Rocalhas. Detalhes das pinturas da Matriz de Santo Antônio, Tiradentes, MG, século XVIII. Técnica: têmpera sobre madeira.

particular. Kellen Cristina acrescenta ainda a posição dos seus pés como uma caligrafia do pintor, denominado por Santos Filho como "pés de bailarina"23

É imprescindível destacar que, no decorrer da catalogação, foram encontradas muitas obras deslocadas de seu lugar de origem, como é o caso dos três quadros pintados em madeira que foram encomendados pela irmandade do Santíssimo Sacramento ${ }^{24}$ para decorar a matriz de Santo Antônio e, no presente, encontram-se expostos no Museu da Liturgia da cidade de Tiradentes. Dentre as pinturas transferidas, encontra-se também o quadro intitulado "A Justiça” que já esteve no Instituto Histórico e Geográfico de Tiradentes e, atualmente, decora o escritório do IPHAN da mesma cidade. Nesses casos, informamos o seu local de origem para que o leitor tenha ciência do seu significado inicial, visto que as obras de arte ganham novos sentidos em novos espaços.

Em 1798, o pintor realizou uma de suas obras mais conhecidas: a pintura e douramento da caixa e da mísula do órgão instalado na nave da igreja (fig.09). ${ }^{25} \mathrm{O}$ artista pintou rocalhas, vasos e ramalhetes de flores; produziu delicados marmorizados nos tons de azul e vermelho; carnou os putti trombeteiros; prateou os tubos da fachada e dourou a talha executada por Salvador de Oliveira. No tocante à ornamentação, de todas as obras visitadas na matriz, a decoração do órgão é a que apresenta as linhas do desenho mais delicadas, formas suaves que proporcionam a leveza do movimento. As cores transitam entre o vermelho e o azul, revelando uma pintura de pouco contraste e a presença do grafismo nas rocalhas. Trata-se de uma técnica artística permanente na sua orna-

\footnotetext{
23 SILVA. O caminho das flores, 2018, p. 416.

24 SANTOS FILHO. Manuel Victor de Jesus, pintor mineiro do ciclo Rococó, 1983,p.233 e 237.

25 Arquivo do Instituto do Patrimônio Histórico e Artístico Nacional (IPHAN), Tiradentes, MG. Livro de Receitas e Despesas da Irmandade do Santíssimo Sacramento de Tiradentes, 1779/1846.
} 
mentação - a hachura. O artista serve-se de linhas paralelas que acompanham a forma do desenho e se cruzam para produzir superfícies de luzes e sombras, criando o volume do objeto. Para as luzes, o pintor empregava o branco; e para as sombras, um tom escuro, normalmente, da mesma cor do objeto pintado (fig.10).

Para finalizar, gostaria de mencionar que o artista decorou duas igrejas completas: as capelas de Nossa Senhora das Mercês ${ }^{26}$ e de Nossa Senhora da Penha de França do Bichinho, ${ }^{27}$ um arraial próximo a Tiradentes que, na atualidade, pertence à cidade de Prados. Pintou inclusive três tetos em perspectiva ilusionista nos referidos templos, sinalizando a existência de um diálogo entre os pintores Manoel Victor e Joaquim José da Natividade, que trabalhou no sul de minas nas primeiras décadas do século XIX. Como praticamente todos os pintores do período colonial, o alferes foi um artista versátil: pintor, dourador, encarnador, desenhista e riscador. Necessário é reforçar que, provavelmente, não existiu uma especialização das artes na região mineradora, do mesmo modo que nas províncias portuguesas, com destaque para as antigas províncias do Entre Douro e Minho e Trás-os-Montes, região norte de Portugal, de onde partiu a maior parte dos artistas que atuaram na capitania de Minas Gerais.

26 Arquivo Eclesiástico da Arquidiocese de São João del-Rei. Livro da Irmandade de Nossa Senhora das Mercês dos Pretos Crioulos, 1787-1888. 


\section{Referências Bibliográficas}

ALMADA, Márcia. Os homens da boa pena e os manuscritos iluminados na Capitania de Minas Gerais no século XVIII. In: Portuguese Literary \& Cultural Studies: The eighteenth century, 2017.

ALVES, Célio Macedo. Minas Colonial: Pintura e Aprendizado. O caso exemplar de João Batista de Figueiredo. In: Telas e Artes. $\mathrm{BH}, \mathrm{n}^{\circ} 15,2000$.

COLI, Jorge. O que é um "Catalogue Raisonné" e para que serve. In: JÚNIOR, Martinho Alves da Costa (org.). Amável Leitor: ensaios de arte e cultura. Juiz de Fora: Editora UFJF, 2019.

GIOVANNINI, Luciana Braga. Os Mistérios do Rosário: visão, contemplação e invocação. estudo iconológico das pinturas de forro da capela de Nossa Senhora do Rosário dos Pretos da vila de São José, Comarca do Rio das Mortes -1750 a 1828. 40of. Dissertação (mestrado em História) - Universidade Federal de São João del-Rei (UFS]), São João del-Rei, 2017.

MARTINS, Hudson Lucas Marques. O Mestre Pintor: A trajetória de João Nepomuceno Correia e Castro \& a Arte da pintura em Minas Gerais nos séculos XVIII e XIX. 145f. Dissertação (mestrado em História). Universidade Federal de Juiz de Fora (UFJF). Juiz de Fora, 2013.

SANTOS FILHO, Olinto Rodrigues dos. Manuel Victor de Jesus, pintor mineiro do ciclo Rococó. In: Barroco 12, 1983.

SANTOS FILHO, Olinto Rodrigues dos. Manoel Víctor de Jesus: 180 anos de morte. Catálogo de exposição de comemoração. Tiradentes, MG: Instituto Histórico e Geográfico de Tiradentes (IHCT), 2008.

SILVA, Kellen Cristina. No silêncio do olhar, a compreensão da palavra: o discurso imagético da religiosidade na irmandade de Nossa Senhora das Mercês de Tiradentes, MG. In: III Encontro Nacional da Imagem. Londrina, PR, 2011.

SILVA, Kellen Cristina. A Mercês crioula: estudo iconológico da pintura de forro da igreja de Nossa Senhora das Mercês dos Pretos Crioulos de São José del-Rei, 1793-1824. 271f. Dissertação (mestrado em História) - Universidade Federal de São João del-Rei, 2012.

SILVA, Kellen Cristina. Um Jesus Esquecido: A Trajetória do Pintor Manoel Victor de Jesus na Vila de São José del-Rei e Entorno, século XIX. In: Revista Kaypunku / Volumen 3 / Número 2 / Junio 2016, pp. 285-319.

SILVA, Kellen Cristina. 0 caminho das flores: estudo iconológico sobre a "Escola de Artes do Rio das Mortes" e o modelo intencional de encomenda - Minas Cerais (c.1785-c.1841). 435f. Tese (doutorado em História). Universidade Federal de Minas Cerais (UFMG), Belo Horizonte, 2018.

OLIVEIRA, Myriam Andrade Ribeiro de. O Rococó religioso no Brasil e seus antecedentes europeus. São Paulo: Cosac \& Naify, 2003. 